\title{
Development of Distributed Generation in China
}

\author{
Minnan Wang, Student Member, IEEE and Jin Zhong, Member, IEEE
}

\begin{abstract}
Rapid economic growth in China requires large amount of electricity supply. When centralized generation (CG) can not provide sufficient electricity supply, distributed generation (DG) draws people's attention. In this paper, the development status and applicability of DGs in China is discussed in detail, and three typical DG utilizations are introduced. Finally, the development of wind generation in China is also examined.
\end{abstract}

Index Terms - Centralized Generation (CG), combined heat and power (CHP), Distributed Generation (DG), Photovoltaic system, Small-hydro generation, Small-thermal generation, Wind Generation.

\section{INTRODUCTION}

$\mathrm{D}$ URING the past few decades China's economy have experienced significant progress with a more than $8 \%$ annual average growth in gross domestic product (GDP) since 1978. As the major energy supply, electricity is essential to the social and economic development. As shown in Fig. 1, the total installed capability in China has reached $713.29 \mathrm{GW}$ by the end of 2007, and it is predicted that this number should reach 1200 GW in 2020 and 2400 GW in 2050. Fig. 2 shows the exploitable capabilities of traditional energy resources, coal $960 \mathrm{GW}$, hydro $360 \mathrm{GW}$, nuclear $260 \mathrm{GW}$, and gas 120 $\mathrm{GW}$, and it is obvious that there is a $720 \mathrm{GW}$ gap between the energy supply ability and demand, which has to be filled by renewable energy resources. In this case, the efficient use of all possible types of alternative resources is highly important to Chinese people [1]. Meanwhile, the Chinese government has realized their responsibilities of protecting the global environment as well as the necessity of sustainable development. With this context, the exploitation of renewable energy has been given a high priority in the energy development strategy.

Another serious problem encountered is that the areas abundant in natural resources are not geographically close to the areas of rapid economic growth. Coal, which is the major primary energy resource, makes up $75.2 \%$ of nationwide energy resources, is mainly distributed in the northern and northwestern part of China. Hydro resource, which is $22.4 \%$ of

\footnotetext{
The work is supported by

Minnan Wang and Jin Zhong are with the Department of Electrical and Electronic Engineering, the University of Hong Kong, HKSAR, China (emails: mnwang@eee.hku.hk, jzhong@eee.hku.hk ).
}

the country's total energy resources, mainly exists in the southwestern part of the country. Oil and gas are mostly located in the east, middle, west areas as well as the coastal areas. On the other hand, the major energy consumption is concentrated in the southeast area, where is more economically developed than other parts of China. Obviously, there is a great discrepancy between the locations of energy resources and consumptions. Therefore, long-distance and high-volume deliveries of coal and oil from the North to the South, and gas and electricity from the West to the East, have become a marked feature and basic mode of China's energy utilization.

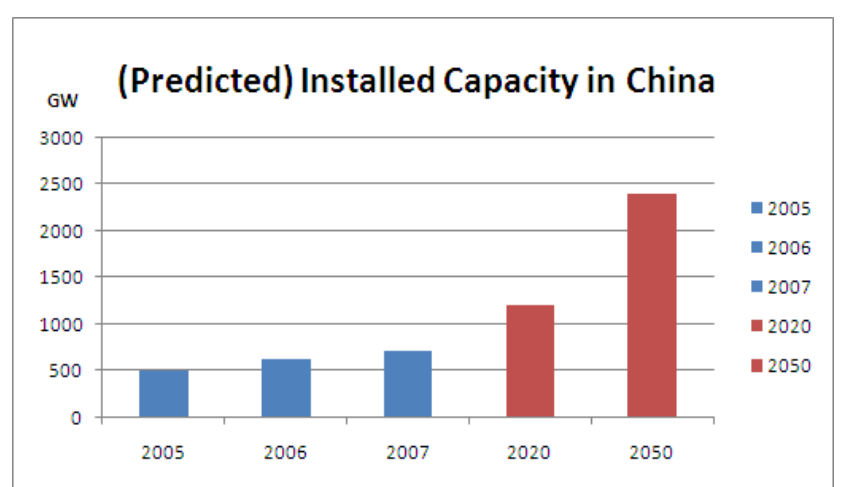

Fig. 1. Total installed capacity in China for years 2005-2007 and predicted total installed capacity in 2020 and 2050.

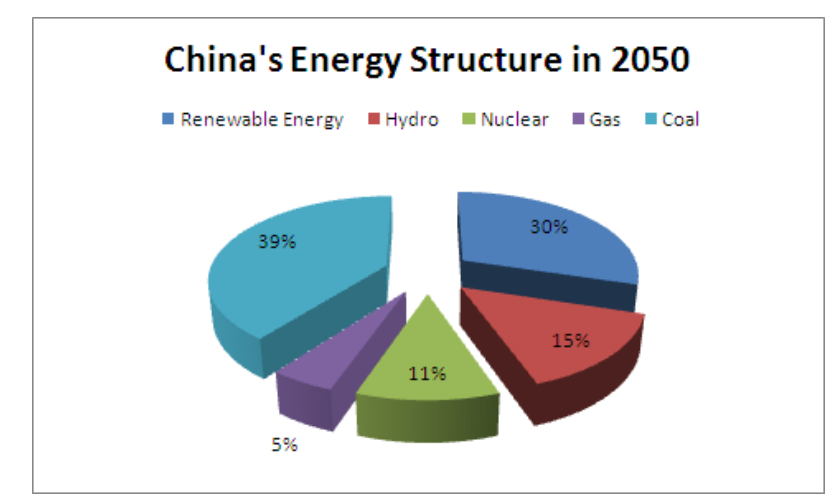

Fig. 2. China's energy structure in 2050.

The recent round of economic boom, especially at its early stage around 2003, requires a significant increase in electricity supply. Due to the long construction cycle of traditional largescale power plants and favorable power-market policies, there emerged many distributed generations in China. Accompanied by the widely-discussed issue of utilizing renewable energy, 
many problems are raised as well. Actually however, distributed generation has never been something new in China. Before the national grid formed its basic structure in 1980s, electricity supply has long been depended on local small power plants, which were mainly developed by the local government utilizing local energy resources.

In this paper, we will introduce the current status of the distributed generation development in China, mainly from the aspects of DG types and the occasions utilized, and their combinations with renewable energy. In section II, the development history of China's power grid is introduced, and the feasibility of developing distributed generations in China nowadays will also be discussed. In section III, how DGs supported China's economic development in the past few decades is introduced, and the current developing trend of DGs is analyzed. In section IV, the other type of utilization of DG in China, to provide electricity supply in remote areas, is introduced. In section $\mathrm{V}$, the new trend of using DGs in urban areas is discussed. Finally in section VI, the important issue of wind power generation in China is briefly introduced.

\section{DG IN ChINA: PAST AND PRESENT}

It is commonly agreed that power systems are of significant economy of scale. As the fixed cost of constructing a centralized power system is high, the average total cost falls continuously as the scale increases. However, after the grid has reached a certain scale, it is both technologically and economically more favorable to develop DGs than concentrated generations (CGs), just as the concept of economy and diseconomy of scale goes in economics. In most developed countries, like the U.S.A and most European countries, the grid scale has surpassed that limit. To further reinforce their power grid into super grids and meanwhile obtain high power quality would be extremely costly. Therefore, to develop DGs to guarantee customers' power quality and reliability has become a trend in these countries.

However, it is not the case in China. In most areas of the country, the grid scales are far below that limit. The power grid in China has a relatively shorter development history than the developed countries, and the investment has long been insufficient. Even nowadays, when there is economic booms, power inadequacy would still become the bottleneck of economic growth. Here we use Supply and Demand Index (SDI) to illustrate the history of China's power supply sufficiency, and how it is related to the speed of economic growth. Here a SDI between 1.000 and 1.030 indicates the power supply and demand is balanced, and electricity availability is not likely to be a limit to economic development A SDI above 1.030 means the energy supply is larger than demand, while below 1.000 warns that there is a power insufficiency. From Fig. 3 we can see that China suffered severe electricity shortage in most of the time during past thirty years, and the most serious power supply shortage perfectly coincided with economic booms in years 1980 to 1986 as well as years 2002 to 2006 [2].

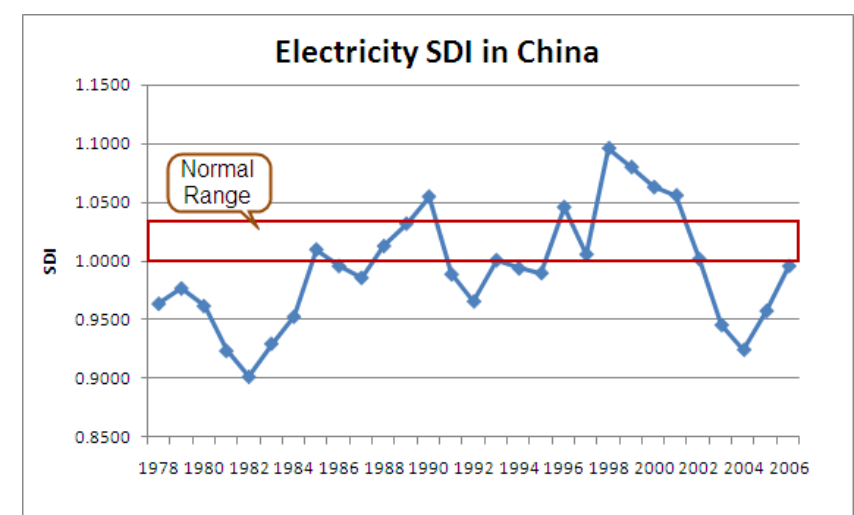

Fig. 3. Electricity SDI in China (1978-2006).

Therefore, we can conclude that the development stage of Chinese power grid is quite different from that of most developed countries. The most emergent goal in current China's power industry is to provide enough electricity supply, rather than improving its over all power quality and stability. That is to say, the focus is currently quantity rather than quality. So it is generally believed that in the current situation of China, developing CGs is both technologically and economically more favorable than DGs, and the government's attitude toward DG's development is mostly negative.

However, at the first stage of power grid's development, as CGs always take much time to reach sufficient scale, it is unavoidable to depend on DG to provide electricity. Before the basic structure of China's centralized grid is formed in the 1980s, the country's power supply is mainly depended on small power plants developed based on local resources. Since early 1970s, the Chinese government started to encourage the local governments to explore different sources to fund the construction of power plants. This policy along with the rapid development of economy in the last two decades of $20^{\text {th }}$ century spurred local governments to construct localized power plants according to their energy resources. Most of these electric stations were running at $10 \mathrm{kV}$ or $35 \mathrm{kV}$ voltage levels, which are classified as distribution networks. These small plants could be defined as Chinese Style DGs, as their roles are quite different from the DGs in most developed countries ---- rather than a supplement to an already strong power system, they are acting as the basic power suppliers.

It is undisputable that these small power plants have greatly supported the economic development of China for a long time. However, the role they are now playing is a widely concerned topic. As it is believed that China's power system has not yet reached the optimal point of economy of scale, CGs are much more preferred as they are regarded more efficient and safer, especially when environmental factors are taken into consideration. Therefore, the development of DGs, in general, is no longer encouraged by the government policy. However, it is impossible for CGs to meet the fast increased electricity demands, and in some circumstances the utilization of DGs is still essentially needed in China, which could be divided into the following three cases:

a) To act as a supplement to the traditional power supply when electricity shortage occurs; 
b) To provide electricity to remote areas which are unable to be covered by CGs;

c) To be used in urban distributed networks to reduce emission and save traditional energy.

In the next three sections, the above mentioned three applications of DGs in China are discussed in details, respectively.

\section{AN IMPORTANT SUPPLEMENT TO TRADITIONAL POWER SUPPLY DURING ELECTRICITY SHORTAGE}

Severe electricity shortage has always been interlocked with economic booms. In China, it is interlocked with prosperous development of distributed generations as well. When insufficiency of CG occurs, there would generally be more favorable market conditions and policies for DGs' development. As China is rich in coal and water resources, most plants built up to meet urgent needs are small-thermal or small-hydro power plants. However, due to their different effects on the environment, the government's policy toward their further development is diametrically opposite. In the following part of this section, the development trace and trend of these two different types of small plants will be introduced.

\section{A. Small thermal and CHP power plants}

Coal is the principal energy source in China, which is $75.2 \%$ of nationwide energy resources and $67.1 \%$ of the country's energy consumption. Being nationwide distributed and especially abundant in the north, meanwhile due to mature thermal generator manufacturing technologies, small thermal power plants have become the most popular small scale power sources all over the country. Most of these stations are of less than 6MW installed capacity and are connected to the grid at $10 \mathrm{kV}$ or $35 \mathrm{kV}$ voltage level. By the end of 2006 , the total capacity of the generators smaller than $6 \mathrm{MW}$ is $21 \mathrm{GW}$, and about $1 / 3$ of the thermal generations in the country are generated by the generators with a capacity smaller than 100MW [3].

Although these small power plants have greatly contributed to the development of the local economy, the environmental problems brought by them have never been ignorable. The average coal consumption of these generators is about $400 \sim$ $700 \mathrm{~g} / \mathrm{kWh}$, while this number for the modern supercritical $600 \mathrm{MW}$ thermal generator is merely $280 \sim 300 \mathrm{~g} / \mathrm{kWh}$ [4]. Added that most small thermal plants have no desulfuration or dust removal equipment, the pollutant discharge of these small plants are far higher than that of large scale generators. Given the same generation production, the dust emitted by small thermal generator is more than 5 times of that of large scale generators, and sulfur dioxide 15 times [5]. Therefore small thermal power plants are regarded as an important source of pollutant emission.

Moreover, the electricity market price set for small thermal generators is relatively high due to their high costs, and the cost can not be compensated if the generation production is not large enough. Therefore as long as these plants are not shut down, the electricity dispatchers have to give them plenty of generation quotas to keep them running, at a price of purchasing expensive electricity. In this sense, the existence these small thermal plants is regarded as a cause power price disorder and further harm the electricity market reform [6].

The development of China's power industry in the middle 1990s eased the discrepancy between power supply and demand, and soon afterwards, the disadvantages of smallthermal plants received more and more attention. From then on, the basic policy is to shut down all the small thermal power units nationwide. However, the execution of this policy met with great obstacles, especially in the years 2001 to 2005, when a new round of economic boom started and serious electricity shortage spread all over China again. The environmental issue and power system restructuring have a lower priority compare to the issue of electricity shortage, therefore the pace of shutting down small thermal generations got slowed down.

Apart from being shut down, small thermal generators are encouraged to be retrofitted into combined heat and power generation (CHP) units if the conditions are favorable. CHP has a long history in China as well. The northern part of China has long bitter winters, and central heating therefore plays an important role in the country's urban public facilities. By the end of 2006, the total centralized heating area is 21.63G with an $85 \mathrm{M}$ annual growth in the past ten years. According to the most recent statistics, the total installed capacity of CHP is more than $48 \mathrm{GW}$, and the total heating capacity is $1.66 \mathrm{G}$ GJ [7]. CHP is regarded as an efficient energy utilization form and therefore greatly encouraged.

\section{B. Small hydro}

Hydro resource is the second major energy source in China. The total hydro reserve is approximately 680GW, and among which small hydro accounts for $87 \mathrm{GW}$, taking up $12.8 \%$. During the past more than twenty years, as shown in Fig. 4, the annual increase of small hydro capacities exceeds $1 \mathrm{GW}$ each year, and this number attained 5GW in 2005 [8]. By the end of 2006, there are 46,989 small hydro power plants nationwide, and the total installed capacity is $45 \mathrm{GW}$, which takes up $37.4 \%$ of China's small hydro exploitable capacity and $34.9 \%$ of the country's hydro capacity [9].

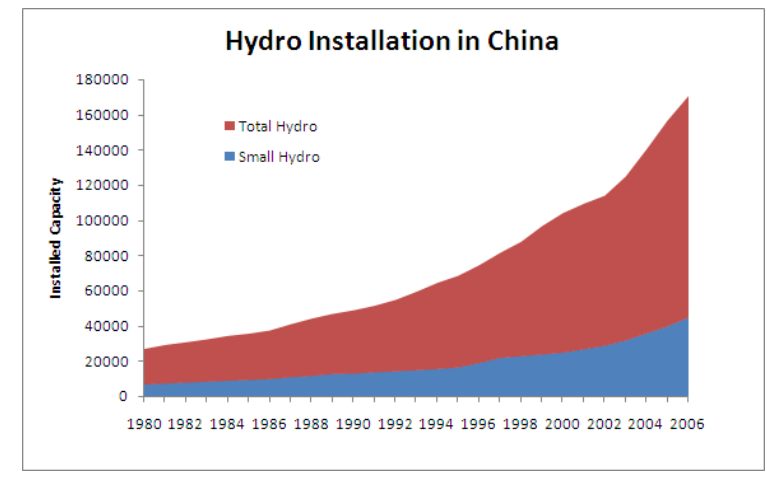

Fig. 4. Hydro installation in China.

The exploit of small hydro generation started in the early 
1950s and experienced significant growth since the 1970s. Due to its economic, technological and environmental advantages, the development of small hydro generation has always been supported by the central government. The development path of Chinese small hydro generation is quite different from that in other developing countries, both in technology and in policy.

\section{1) Technologies}

Most small hydro power plants in China have their own local networks and are connected to the state grid at a point of common coupling. As there are clear high and low water head seasons in China while the former ones mainly appear in summer and the latter ones in winter, it is quite common that there is electricity surplus in the summer and shortage in the winter. This problem is solved mainly by dual-adjusting planning. On one hand, power source sites are selected not only based on the economic optimization of the plant itself, but also the global optimization of the local network operation. On the other hand, loads are planned according to the amount of electricity available. Adding certain amount of controllable load, like crop dryer and electric boiler etc., into each network in the summer and shut them down in the winter, electricity generated in high water seasons can be fully utilized while in the winter, basic residential, industrial and commercial electricity supply is guaranteed.

2) Government policy

The government policy toward the development of small hydro generation has been continuously favorable. These policies including:

a. Tax exemption for small hydro power plants. All the profits they made can be used for self development.

b. Within the areas whose power is supplied by small hydro power plants, an extra 2 cents/kWh is levied as rural hydro generation development foundation.

c. Income tax deduction from $33 \%$ to $100 \%$, varying provincially.

d. Specially designed electricity market price for hydropower, mostly equal to the sum of cost, tax and proper profit.

e. Guarantee the supply district of small hydro power units. In order to protect the market share of small hydro power plants, stated grid is forbidden to compete with small hydro plants in their local networks.

With these favorable conditions, small hydro generation is developed rapidly with promising futures. It is predict that by the year of 2020, the total installed capacity will reach 75GW nationwide.

\section{REMOTE AREAS}

Another important utilization of DGs in China is to provide basic electricity supply to remote areas. There is a vast territory sparsely populated in the northwest part of China, where the average population density is $8 / \mathrm{km}^{2}$ and therefore, covering the areas with large power systems is disadvantaged both technically and economically. Luckily, these areas are rich in solar energy which is favorable for developing distributed generation. According to the solar energy distribution map shown in Fig. 5, most parts in the northwestern China is endowed with a Total Solar Radiation more than $7500 \mathrm{MJ} / \mathrm{m}^{2}$ each year. And this advantage has been taken by the local residents and governments to generate electricity to meet their needs in daily lives.

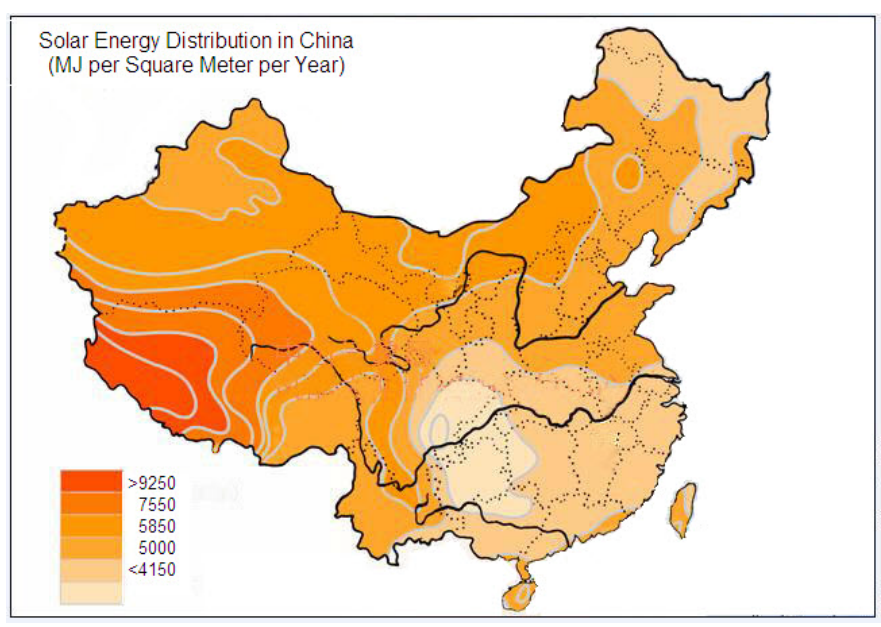

Fig. 5. Solar Energy Distribution in China.

By the end of 2005, the total installed capacity of photovoltaic (PV) panels is around 70MW, among them the majority is used to provide electricity supply to residential customers in remote areas. Most of them are household PV systems, while several solar power plants are also installed, with capacities less than 1MW. Fig. 6 shows the development of PV installation since 1970 in China. It is predicted that by the year of 2020, the total installed capacity will reach 300MW and will electrically supply another 3 million families [10].

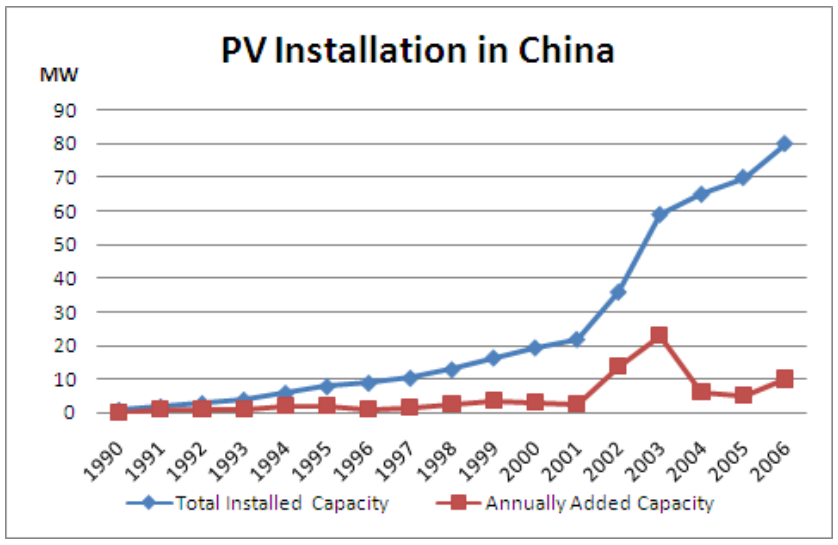

Fig. 6. PV installation in China (1975-2005).

\section{PV SySTEMS IN URBAN DistRIBUTION NETWORKS}

In urban areas, especially in metropolitans like Beijing and Shanghai, where distribution networks are relatively strong, loads are concentrated and environmental requirements are relatively high, people is starting to get appealed to PV roof plans. Some provinces in the eastern China with high 
economic developed speeds have planned to build up more PV roof systems. For example, Shanghai government has initiated "a hundred thousand PV roof project" in 2006, planning to install PV systems on a hundred thousand roofs in the city, with the total size of three million square meters and the total capacity of 500MW, within the next ten years [13]. The National Stadium, one of the key venues of 2008 Beijing Olympic Games, has installed a PV roof system with an annual power generation of 97MWh. Similar systems are also planned to be utilized in the 2010 Shanghai World Expo and the 2010 Guangzhou Asian Games [14].

The main obstacle faced by the PV roof system is its high cost. The electricity price is around ten times than that of traditional electricity, not accounting the initial installation costs. And also people in large cities tend to care more about the aesthetic property of their buildings, while current PV technologies failed to take that into consideration. Some scholars have compared PV roof systems as computers in the 1980s ---- we know its future is promising, but we have to wait for the technology to cut the cost to an acceptable level [15].

\section{WIND GENERATION}

The development of DG is always connected to the utilization of renewable energy, as renewable energy is often dispersedly distributed and does not result in much pollution to the nearby customers. Among all the non-hydro renewable energies, wind generation has the most favorable technical and economic advantages, and therefore special stress has been laid on its exploitation in recent years. Fig. 7 shows the installed capacity of wind generation in China in years 1995 to 2007. According to the statistics published by National Academy of Meteorological Sciences, the exploitable wind capacity at $10 \mathrm{~m}$ above ground level is $253 \mathrm{GW}$, and its offshore capacity is approximately three times of this number. It is predicted that in the year of 2020, the total installed capacity of wind generation will reach $30 \mathrm{GW}$, and wind energy is going to take over and become the third major energy resource to generate electricity in China, while in 2050 will take over water as the second one [11].

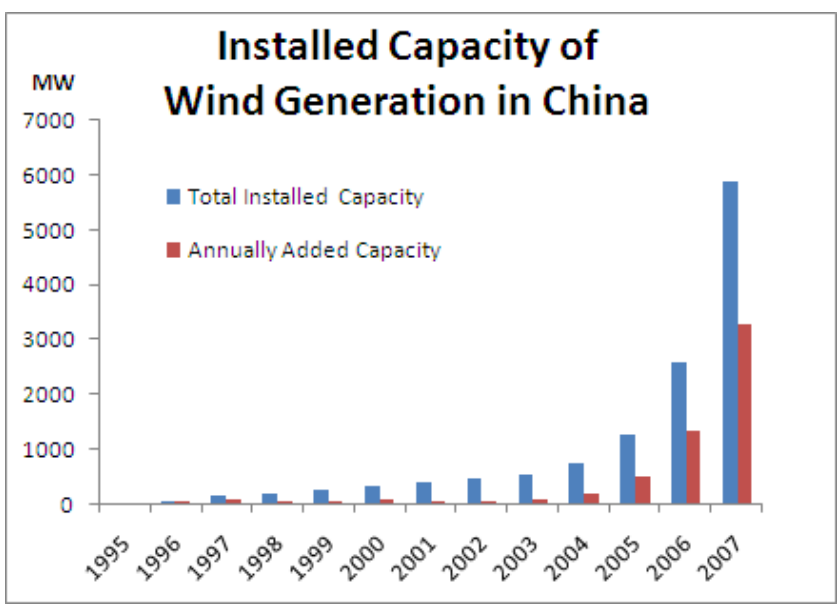

Fig. 7. Installed Capacity of Wind generation in China.
However in China, wind energy is greatly centralized and unevenly distributed. As shown in Fig. 8, over $70 \%$ of the country's wind resource is in the six provinces, InnerMongolia, Tibet, Gansu, Xinjiang, Qinghai and Heilongjiang in the north. Therefore, the state's main policy is to centrally utilize wind energy to generate electricity in windy area, and transmit the wind power to the other parts of China via ultrahigh-voltage (UHV) transmission systems. The biggest wind farm under construction in China is located in Gansu province, with a planned total installed capacity of more than 10GW. Meanwhile, a $750 \mathrm{kV}$ UHV transmission line is also being planned to transmit the electricity to the load intensive areas [1].

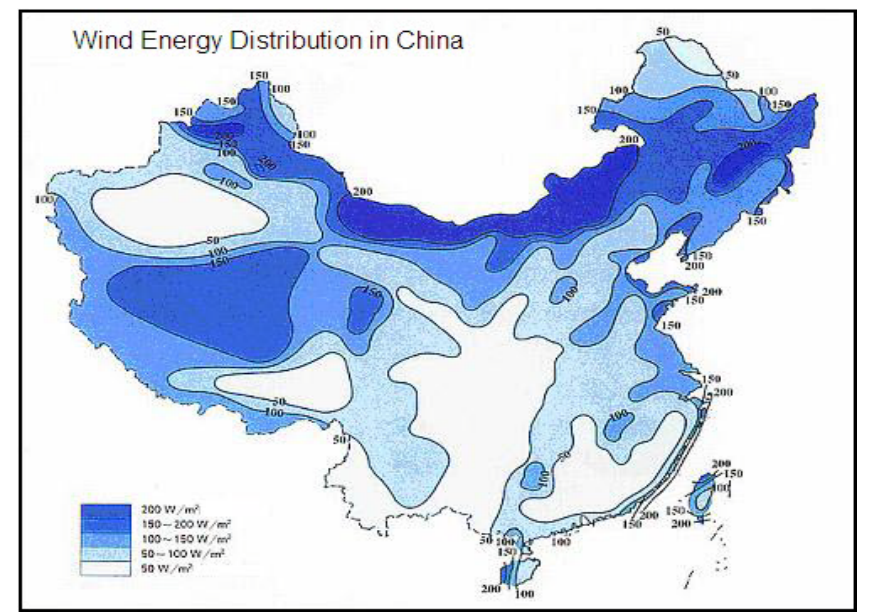

Fig. 8. Wind Energy Distribution in China.

On the other hand, the offshore wind resource is mainly located in the southeast part, whose exploitable capacity is three times of that on land [12]. Electricity load is concentrated in this area as well, therefore the grid structure is relatively strong and less technical problem is likely to occur [11]. Large offshore wind farms are also being planned to provide electricity to its neighborhood areas.

Fig. 7 shows the total installed capacity from 1995 to 2007 respectively [1]. To further encourage the development of wind generation, in the year of 2003, the State Development and Reform Commission (SDRC) launched Wind Power Concession Projects (WPCP), which greatly accelerated wind generation development. The main ideas of WPCP are:

a. The government selects developers via public auctions, and those with lowest market prices win the bid.

b.Provincial grid companies should sign contracts to promise the purchase of the whole amount of electricity generated by wind farms.

c. Price difference should be compensated by the provincial grid companies.

After the execution of four rounds of WPCP, the main obstacles existed in wind generation development before 2002 were successfully resolved. However, problems regarding wind power purchasing prices and amount revealed their significance. 


\section{A. Price}

In years 2003 to 2006, there are eleven WPCP bids invited, and due to over competition, as shown in Fig. 9, the knocked down prices are lower than their costs without exception. This fact has caused most developers lost their passions in developing wind farms in China, and the big state owned generation companies gets the lion's share of the market.

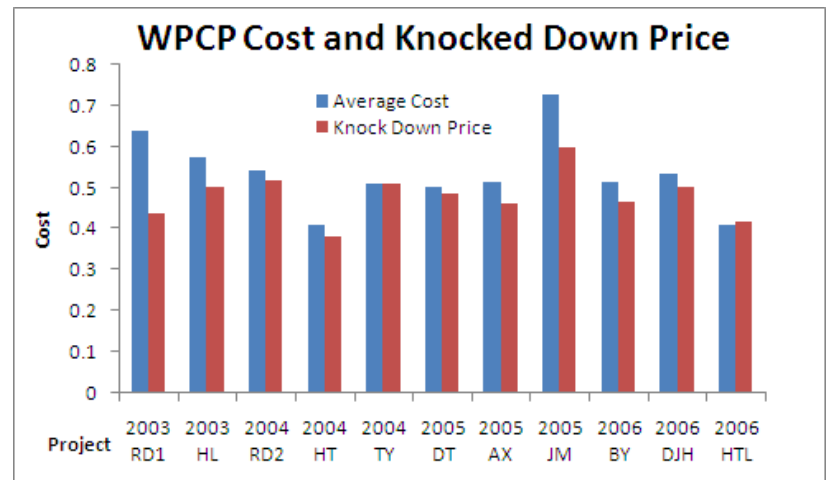

Fig. 9. WPCP Cost and Knock Down Price.

\section{B. Amount}

Although the provincial grid companies have promised to purchase all the electricity generated by wind, no one could deny that wind energy is an intermittent power source and would sometimes unavoidably affect the safety, reliability and economy of the grid operation. Moreover, as the northwestern provinces are less developed areas, their local grids are pretty weak. Therefore in practice, the provincial grid companies can hardly fulfill their commitments. On the other hand, wind farm owners claim that their electricity is not purchased due to economical reasons rather than technical reasons, as the market price of electricity generated by wind is higher than that of traditional energies, and the price differences are supposed to be compensated by the provincial grid companies.

\section{Solutions}

To resolve these problems, SDRC has amended the rules in WPCP in two aspects in 2005 and 2006 respectively: 1) market price only accounts for $40 \%$ of the bidding decision weight and 2) the price difference between wind generated electricity and traditional energy generated electricity shall be compensated by the State Grid. Due to these positive rules, wind generation kept its fast development speed in China and according to the statistics published by GWEC, the total capacity of wind generation has reached 6050WM by the end of 2007.

\section{CONCLUSIONS}

In this paper, we first analyzed the current status of China's power grid development, compared the applicability of developing DGs and CGs, and concluded that at present the use of CGs in China is both economically and technologically more favorable. Then three typical applications of DGs in China are discussed respectively, which are:

a) To act as a supplement to traditional power supply when electricity shortage occurs. Most DGs used in this case are small thermal and small hydro plants. For small thermal plants, due to their unfavorable environmental effect and high cost, their developments are no longer encouraged by the government. But for small hydro plants, as they are cheap and clean, the future prospect of their development is very promising.

b) To provide electricity to remote areas which are unable to be covered by CG. DGs used in this case are mainly small scale PV systems. As there is still a large population in the remote areas not supplied with electricity, this market of cheap and simple PV systems could be expected to expand continuously for a long time from now on.

c) To be used in urban distributed networks to reduce emission and save traditional energy. Grid structure in some metropolitans in China is quite similar to that of big cities in developed countries, and people have started to tentatively utilize DGs to improve their power quality and save traditional energy. Several projects have been carried out in Beijing, Shanghai and Guangzhou etc., and we could expect this market to be of high prosperity in the long run.

Finally the development of wind generation in China is examined, and the problems encountered by the execution of WPCP and their solutions are introduced.

From this paper we can conclude that although the current focus of China's power system construction is CG, DGs have their own advantages in solving certain problems encountered by the country's development. Especially when combined with the utilization of renewable energies, which are favorable to solve the energy strategy challenges, DGs' development in China is of a highly promising future.

\section{REFERENCES}

[1] Y. J. Cao, and X. X. Zhou, "The future of China to develop non-hydro renewable sources power generation," Journal of Electric Power Science and Technology, vol. 23, pp. 2-7, 2008.

[2] Z. G. Hu. (2008, Sep.). Research on the Electricity Supply and Demand Index.[Online].Available:http://www.studa.net/qiyeyanjiu/080910/1603 5190.html.

[3] P. Z. Wang, "The development of China's small-thermal plants' shutting down and large-thermal plants'," Generation Equipment, vol. 1, pp. 9396, 2008.

[4] C. Z. Chen, "Strictly control the construction of small-thermal generation, simulate the development of energy saving and environmental friendly society," Energy and Environment, vol. 5, pp. 23, 2006.

[5] Q, H, Shang, H, Q, Li, and J, S, Fang, "Survey on China's small thermal generation," Management of China's Electrical Power Corporations, vol. 9, pp. 49-50, 2006.

[6] D. P. Wang, "The management of small-thermal," Energy Management, vol. 9, pp. 37-39, 2002.

[7] H. Kang, and X. K. Guo, "Developing co-generation plants to ease pressure on energy," Electric Power Construction, vol. 28, pp. 40-43, 2007.

[8] Z. J. Wang, and T, F, Zou, "Discussion on the problems exist in China's small-hydro generation construction," China Rural Hydro Generation, vol. 2, pp. 82-85, 2007.

[9] M. W. Jiang, "Discussion on China's small-hydro generation development," Rural Hydro Generation, vol. 1, 2008. 
[10] National Development and Reformation Commission of PRC, "Longterm planning on the development of renewable energy resources," 2007.

[11] Q. Ai, and J, Jin, "Current status assessment and future development prospect of China's wind farm construction," Electrical Power of Eastern China, vol. 35, pp. 44-49, 2007.

[12] G. Y. Yan, and Y, B, Xiao, "Brief introduction on current status and future development of China's wind generation," Department Stores Modernization, vol. 24, pp. 216, 2008.

[13] Y. F. Chu, "Current status of China's photovoltaic roof system," Journal of Mudanjiang Normal University, vol. 2, pp. 47-48, 2008.

[14] Y. F. Chu, "Problems and Solutions on the development of photovoltaic roof system," Journal of Jingmen Technical College, vol. 6, pp. 23-26, 2008.

[15] Z. J. Wang, and T, F, Zou, "Close investigation of China's two photovoltaic roof systems," Photovoltaic Project, 2008.

\section{BIOGRAPHIES}

Minnan Wang graduated from the department of Electrical Engineering of Tsinghua University, Beijing, China, in 2008, and is now working on her MPhil degree at the University of Hong Kong, HKSAR, China.

Jin Zhong (M'04) received the B.Sc. degree from Tsinghua University, Beijing, China, in 1995, the M.Sc. degree from China Electric Power Research Institute, Beijing, in 1998, and the Ph.D degree from Chalmers University of Technology, Gothenburg, Sweden, in 2003. At present, she is an Assistant Professor in the Department of Electrical and Electronic Engineering of the University of Hong Kong. Her areas of interest are electricity sector deregulation, ancillary service pricing, and distributed generation. 